Chronic Obstructive Pulmonary Diseases: Journal of the COPD Foundation

\author{
Original Research
}

\title{
Randomization to Omega-3 Fatty Acid Supplementation and Endothelial Function in COPD: The COD-Fish Randomized Controlled Trial
}

\author{
John S. Kim, MD, MS ${ }^{1,2^{*}}$ Michael A. Thomashow, MD ${ }^{1,3^{*}}$ Natalie H. Yip, MD ${ }^{1}$ Kristin M. Burkart, MD, MSc ${ }^{1}$ \\ Christian M. Lo Cascio, MD ${ }^{1}$ Daichi Shimbo, $\mathrm{MD}^{1}$ R. Graham Barr, MD, DrPH ${ }^{1,4}$
}

\section{Abstract}

Rationale: Studies suggest a pathogenic role of endothelial dysfunction in chronic obstructive lung disease (COPD). Omega-3 (n-3) polyunsaturated fatty acid (PUFA) supplementation improves endothelial function in other diseases but has not been examined in COPD.

Objective: We hypothesized that n-3 PUFA supplementation would improve systemic endothelial function in COPD. We performed a pilot randomized, placebo-controlled, double-blind, phase 2 superiority trial (NCT00835289).

Methods: Adults with moderate and severe stable COPD (79\% with emphysema on computed tomography [CT]) were randomized to high-dose fish oil capsules or placebo daily for 6 months. The primary endpoint was percentage change in brachial artery flow-mediated dilation (FMD) from baseline to 6 months. Secondary endpoints included peripheral arterial tonometry, endothelial microparticles (EMPs), 6-minute walk distance, respiratory symptoms, and pulmonary function.

Results: Thirty-three of 40 randomized participants completed all measurements. Change in FMD after 6 months did not differ between the fish oil and placebo arms $(-1.1 \%, 95 \%$ CI $-5.0-2.9, p=0.59)$. CD $31^{+}$EMPs increased in the fish oil arm (0.9\%, 95\% CI 0.1-1.7, p=0.04). More participants in the fish oil arm reported at least a 4-point improvement in the St George's Respiratory Questionnaire (SGRQ) compared to placebo (8 versus $1 ; p=0.01$ ). There were no significant changes in other secondary endpoints. There were 4 serious adverse events determined to be unrelated to the study ( 3 in the fish oil arm and 1 in the placebo arm).

Conclusion: Randomization to n-3 PUFAs for 6 months did not change systemic endothelial function in COPD. Changes in EMPs and SGRQ suggest n-3 PUFAs might have biologic and clinical effects that warrant further investigation.

\footnotetext{
Abbreviations: chronic obstructive pulmonary disease, COPD; Omega-3, n-3; polyunsaturated fatty acid, PUFA; computed tomography, CT; flow-mediated dilation, FMD; endothelial microparticles, EMPs; St George's Respiratory Questionnaire, SGRQ; Chronic Obstructive Pulmonary Disease Fish Oil trial, COD-Fish; forced expiratory volume in 1 second, FEV $\mathbf{1}$; forced vital capacity, FVC; eicosapentaenoic acid, EPA; docosahexaenoic acid, DHA; peripheral arterial tonometry, PAT; reactive hyperemia index, RHI; phycoerythrin-conjugated, PE; fluorescein isothiocyante-conjugated, FITC; American Thoracic Society, ATS; European Respiratory Society, ERS; diffused capacity of the lungs for carbon monoxide, DLCO; 6-minute walk test, 6MWT; modified Medical Research Council, mMRC; alveolar volume, VA; total lung capacity, TLC; high density lipoprotein, HDL; low density lipoprotein, LDL; alanine aminotransferase, $\mathbf{A L T}$; standard deviation, SD; oxygen saturation, $\mathbf{S p O}_{2}$; serious adverse events, SAEs; peroxisome proliferator-activated receptor gamma, PPAR- $\boldsymbol{\gamma}$; specialized pro-resolving lipid mediators, SPMs; calcium channel blocker, ССB

Funding Support: National Institutes of Health/National Heart, Lung and Blood Institute R01-HL077612, R01-HL093081, T32HL-105323, National Institutes of Health/National Institute of Environmental Health Sciences Center Pilot Award ES009089, RR024156. Omax-3 and placebo were provided by an in-kind donation from Cenestra Health. Clinical Trial Registration: NCT00835289

Date of Acceptance: August 14, 2020 | Published Online Date: November 2, 2020

Citation: Kim JS, Thomashow MA, Yip NH, et al. Randomization to omega-3 fatty acid supplementation and endothelial function in COPD: the COD-FISH randomized controlled trial. Chronic Obstr Pulm Dis. 2021;8(1):41-53. doi: https://doi.org/10.15326/ jcopdf.8.1.2020.0132
} 
1 Department of Medicine, Columbia University Irving Medical Center, New York, New York, United States

2 Department of Medicine, University of Virginia School of Medicine, Charlottesville, Virginia, United States

3 Kaiser Permanante San Francisco Medical Center, San Francisco, California, United States

4 Department of Epidemiology, Mailman School of Public Health, Columbia University Irving Medical Center, New York, New York, United States

* Both authors contributed equally to the manuscript.

\section{Address correspondence to:}

R. Graham Barr, MD, DrPH

Columbia University Irving Medical Center

Presbyterian Hospital 9 East 105

630 West 168th Street, New York, NY 10032

rgb9@columbia.edu

\section{Keywords:}

fatty acid; emphysema; endothelium; chronic obstructive lung disease

\section{This article has an online supplement}

\section{Introduction}

Chronic obstructive lung disease (COPD) is the third-leading cause of death worldwide and the fourth-leading cause in the United States. ${ }^{1}$ Mortality from COPD has not dropped appreciably ${ }^{2}$ over the last 3 decades despite large reductions in cigarette smoking. No new classes of medical therapy have been approved for COPD in recent years. ${ }^{3}$ Therefore, alternative mechanistic pathways with preventative and therapeutic implications warrant examination.

While chronic inflammation and mucus hypersecretion resulting in small airways narrowing is one of the major underlying mechanisms of COPD, ${ }^{4,5}$ the role of endothelial function in the pathogenesis of COPD has been investigated and may be a therapeutic target. ${ }^{6}$ Lung tissue from COPD patients with significant emphysema is marked by increased endothelial apoptosis and decreased expression of vascular endothelial growth factor compared to normal human lung tissue. ${ }^{7,8}$ Endothelial dysfunction of the pulmonary arteries occurs in COPD with normoxia, suggesting it might be an early feature of disease. ${ }^{9}$ Reduced flow-mediated dilation (FMD) of the brachial artery and higher circulating levels of endothelial microparticles (EMPs), non-invasive measures of systemic endothelial function, are associated with greater emphysema on computed tomography (CT) and lower lung function and diffusing capacity. ${ }^{10-13}$
Omega-3 (n-3) fatty acids are polyunsaturated fatty acids (PUFAs) characterized by a double bond at C-3 in their hydrocarbon chain and may improve endothelial function by enhancing the release of nitric oxide and reduce inflammatory cytokine production. ${ }^{14-16}$ Supplementation with n-3 PUFAs (i.e., fish oil) improved FMD and reduced circulating levels of vascular endothelial dysfunction surface markers in coronary artery disease. ${ }^{17,18}$ These findings for intermediate endpoints, however, have not translated into reduced cardiovascular events. ${ }^{19-21}$ Crosssectional and longitudinal observational studies have been conflicting in regards to the association of n-3 PUFA intake with risk of COPD, lung function, and symptoms, ${ }^{22,23}$ and are potentially limited by unmeasured confounding.

We, therefore, performed the Chronic Obstructive Pulmonary Disease Fish Oil (COD-Fish) pilot trial to evaluate the efficacy and safety of n-3 PUFA supplementation among former smokers with stable COPD, hypothesizing that randomization to n-3 PUFAs would improve endothelial function as measured by FMD and other measures of endothelial health.

\section{Methods}

\section{Study Design and Participants}

COD-Fish was a prospective, randomized, placebocontrolled, double-blinded superiority trial conducted at Columbia University Medical Center from March 2009 to October 2012. Written informed consent was obtained from all participants. The study's protocol was approved by the Columbia University Institutional Review Board. The study was registered at clinicaltrials.gov prior to enrollment (NCT00835289).

Full inclusion and exclusion criteria are listed in Table $\mathrm{S} 1$ in the online supplement. Briefly, participants were former smokers with at least a 10 pack-year history who were older than 40 years of age, had post-bronchodilator forced expiratory volume in 1 second $\left(F E V_{1}\right)$ to forced vital capacity (FVC) ratio $<70 \%$ and post-bronchodilator $\mathrm{FEV}_{1}<65 \%$ predicted, and were on a stable medical regimen for 30 days prior to enrollment. Major exclusion criteria included an allergy to fish or corn oil, history of cardiovascular disease, left-sided congestive heart failure, coronary artery disease, peripheral vascular disease, stroke, 
prior lung resection, sleep apnea, Raynaud's phenomenon, congenital abnormality of the arm or hand, end stage liver disease, and history of radical mastectomy (Table $S 1$ in the online supplement).

After screening, participants were randomized in a $1: 1$ ratio by research study coordinators to receive 3 soft gel capsules that contained $650 \mathrm{mg}$ of eicosapentaenoic acid (EPA) (20:5, n-3) and 182mg of docosahexaenoic acid (DHA) (22:6, n-3) (Omax3, Cenestra Health) for a total daily dose of 3 grams of n-3 PUFAs or 3 soft gel capsules of placebo (corn oil, Prevention Pharmaceuticals, Inc.) daily for 6 months. There were no prior trials that examined the effect of $n-3$ PUFAs on FMD in adults with COPD at the design and start of this study. Therefore, the dose and duration of our intervention were based on prior studies that examined the effect of $n-3$ PUFAs on FMD in other chronic inflammatory diseases. ${ }^{24,25}$ Inactive ingredients in Omax3 include vitamin E/tocopherol $2294 \mathrm{ppm}$, gelatin, glycerol, and purified water. The placebo capsule had the same appearance and smell as the active capsule unless the capsule was broken or bitten. In order to minimize gastrointestinal effects when starting high-dose n-3 PUFA, all participants were instructed to take 1 capsule daily for 1 week, then 2 capsules daily for 1 week, followed by 3 capsules daily for the remainder of the study. At each followup visit, compliance with treatment was assessed (see the online supplement for a full description). All participants, investigators and study personnel were blinded to treatment assignment.

Follow-up visits occurred at 2, 4, and 6 months from baseline. Timing of outcome assessments is summarized in Table S2 in the online supplement. Adverse events were summarized at every visit.

\section{Study Endpoints}

\section{Flow-mediated Dilation:}

FMD was measured using a standardized protocol as previously described. ${ }^{10,26}$ Briefly, participants fasted, avoided exercise, and withheld all oral medications for 8 hours and rested in a supine position for 15 minutes prior to measurement. Brachial artery diameter was measured at least $3 \mathrm{~cm}$ to $7 \mathrm{~cm}$ above the antecubital fossa of the right arm using B-mode ultrasound with a $15-\mathrm{MHz}$ linear array transducer (SONOS 5500; Philips, Andover, Massachusetts). A blood pressure cuff (automatic sphygmomanometer, Dinamap) was inflated to $200 \mathrm{mmHg}$ or at least $50 \mathrm{mmHg}$ above the systolic blood pressure for 5 minutes to occlude the arterial flow, then the brachial artery diameter was remeasured during reactive hyperemia and recorded at its largest diameter for the maximum post-deflation diameter and 1 minute after cuff deflation for the 55-65 second deflation diameter. ${ }^{26-28}$ End-diastolic images were digitized by a frame grabber (model LG3; Scion Corporation, Frederick, Maryland). Brachial artery diameters were measured by a single reader blinded to participant information using analysis software for 3 consecutive cardiac cycles at rest and 1-minute post-deflation. FMD was expressed as percentage change from rest $(100 \times$ [brachial artery diameter during reactive hyperemia-diameter at rest]/diameter at rest).

\section{Peripheral Arterial Tonometry:}

Peripheral endothelium-dependent vasodilation was assessed by a peripheral arterial tonometry (PAT) device (EndoPAT2000, Itamar Medical, Caesarea, Israel) as previously described ${ }^{29,30}$ under the same conditions as for FMD. Reactive hyperemia was induced as for FMD. The PAT probe is a pneumatic plethysmograph that measures pulse volume changes providing a measure of the micro-arterial smooth muscle tone in the fingertip. Each pulse wave was digitally recorded continuously from 10 minutes before cuff inflation (resting) to 10 minutes after cuff deflation. The reactive hyperemia index (RHI) was calculated as the ratio of the average amplitude of the peripheral arterial tonometry signal between 90- and 120-seconds post-deflation divided by the average amplitude of the signal of the resting period. RHI values from the study finger were normalized to a control finger on the other hand. ${ }^{29}$

\section{Endothelial Microparticles:}

The preparation and measurement of EMP have been previously described. ${ }^{11,31,32}$ Venous blood samples were drawn into citrated tubes after participants underwent at least an 8-hour fast. EMPs were assayed within 2 hours of phlebotomy. Fifty $\mu \mathrm{L}$ aliquots of platelet-poor plasma was incubated with the following:

(1) $4 \mu \mathrm{L}$ of phycoerythrin-conjugated monoclonal antibody for CD31 (AbD Serotec, Cat. no. MCA $1738 \mathrm{PE}$ ) and $4 \mu \mathrm{L}$ of fluorescein isothiocyante-conjugated (FITC) monoclonal antibody to CD42b (AbD Serotec, Cat. no. MCA 
$740 \mathrm{~F})$

(2) $4 \mu \mathrm{L}$ of PE-conjugated monoclonal antibody to CD51 (AbD Serotec, Cat. no. MCA 757 PE) plus $4 \mu \mathrm{L}$ of FITC-conjugated monoclonal antibody to $\mathrm{CD} 42 \mathrm{~b}$; and

(3) $4 \mu \mathrm{L}$ of PE-conjugated monoclonal antibody to CD62E (BD, Cat. no. 551145).

Flow cytometry was performed on a BD FACSCalibur.

EMPs were defined as microparticles positively labeled by CD31 and negatively labeled by CD42 $\left(C D 31^{+}\right.$EMP); positively labeled by CD51 and negatively labeled by CD42 (CD 51 ${ }^{+}$EMPs); and positively labeled by CD62E (CD62 ${ }^{+}$EMPs). CD42 labeling was used in conjunction with CD31 and CD51 to exclude the unintended measurement of platelet microparticles. The threshold for particle size on forward light scatter was first determined using $1.5 \mu \mathrm{m}$ calibrator beads (Bang Laboratories, Inc), and the number of EMPs (CD $31^{+}$, and separately CD $51^{+}$, and $\mathrm{CD} 2 \mathrm{E}^{+}$) with size $<1.5 \mu \mathrm{m}$ was counted at a medium flow rate for a 30 -second period. Standard beads were used to convert flow cytometer counts to an estimate of number of EMPs per $\mu \mathrm{L}$ of blood. Appropriate FITC- and PE-labeled isotype-matched mouse monoclonal immunoglobulin $G$ was used to determine non-specific binding of fluorescent antibodies.

\section{Lung Function and Diffused Capacity of the Lungs for Carbon Monoxide:}

Pre- and post-bronchodilator spirometry were conducted in accordance with American Thoracic Society/European Respiratory Society (ATS/ERS) guidelines on a dry-rolling-sealed spirometer (Occupational Marketing, Inc., Houston, Texas). ${ }^{33,34}$ Post-bronchodilator spirometry was performed 15 to 20 minutes after inhalation of 2 puffs of albuterol $(180 \mathrm{mcg})$. COPD was defined as a postbronchodilator $\mathrm{FEV}_{1} / \mathrm{FVC}$ ratio $<70 \%{ }^{35,36} \mathrm{COPD}$ severity was classified as moderate, $\mathrm{FEV}_{1}$ 50\%-80\% predicted; severe, $\mathrm{FEV}_{1}$ 30\%-50\% predicted; and very-severe, $\mathrm{FEV}_{1}<30 \%$ predicted. ${ }^{3,37}$ Predicted values were calculated using Hankinson reference equations with a 0.88 correction for Asians. ${ }^{34,38}$

Single-breath diffused capacity of the lungs for carbon monoxide (DLCO) was measured at baseline and at 6 months with an EasyOne Pro DLCO (Ndd Medical Technologies, Andover, Massachusetts) following ATS/ERS guidelines. ${ }^{39}$ The average of all acceptable tests (minimum of 2 tests) was reported. Breath-hold time was assessed by the method of Jones and Meade. ${ }^{40}$

\section{Six-Minute Walk Test:}

The 6-minute walk test (6MWT) was performed in accordance with guidelines at each study visit. ${ }^{41}$

\section{Questionnaires:}

Quality of life and dyspnea were assessed with the St George's Respiratory Questionnaire (SGRQ) and the modified Medical Research Council (mMRC) dyspnea scale. ${ }^{42-44}$

\section{Other Measures:}

Standing height and weight was measured with a balance scale and rod. Smoking status was selfreported by the participant and verified using NicAlert ${ }^{45}$ cotinine test strips in saliva. At the last study visit, participants were asked in a questionnaire whether they thought they received placebo or the study treatment to assess adequacy of randomization. Emphysema was determined based on reports from available CT scans performed prior to enrollment in the trial.

\section{Statistical Analysis}

The primary endpoint was the absolute betweengroup difference in the change in percentage FMD from baseline to the end of the trial at 6 months. Secondary endpoints included absolute betweengroup differences in changes in RHI, EMPs, pulmonary function, 6-minute walk distance (6MWD), SGRQ and the mMRC dyspnea scale. We used linear mixedeffects models to examine between-group changes in FMD, secondary end points, and lipids following the intention-to-treat principle. We modeled all repeated outcome measurements with random slope and intercept terms in addition to an interaction between randomized assignment and time. This model has the advantage of allowing for repeated endpoints, controlling for potential imbalances at baseline randomization due to the small sample size and treating missing endpoint data as missing at random. Also, a normal range for FMD and RHI have not been determined as prior studies have shown a wide range of these values in healthy adult populations, which is why we assessed the change in FMD and RHI over time using linear mixed-effects models. ${ }^{26}$ Endpoints 
were treated as continuous terms and, when clinically significant thresholds were available (e.g., 4-point improvement in their SGRQ score from baseline to the end of the study ${ }^{46}$ ), as dichotomous terms using the chi-square test.

Using an observed mean change in FMD with high-dose n-3 PUFA supplementation of $0.085 \mathrm{~mm}$ compared to a mean change of $0.08 \mathrm{~mm}$ in the placebo group based on a prior study, ${ }^{24}$ we estimated $80 \%$ power to detect a between-group difference of 0.08 $\mathrm{mm}$ with a sample size of 18 participants in each arm using a 2-tailed alpha of 0.05 . To account for a $10 \%$ dropout rate, we recruited a total of 40 participants into the trial. Analyses were performed using SAS version 9.4 (SAS Institute).

\section{Results}

\section{Baseline Characteristics}

The randomized sample included 40 participants, 20 in each arm (Figure 1). Baseline characteristics are summarized in Table 1. All participants had at least moderate COPD and reported no active use of nicotine-containing products, which was confirmed by NicAlert testing. A total of 34 participants had CT data available, of which 27 (79\%) had emphysema. At baseline, the fish oil arm had a higher mean 6MWD, lower systolic and diastolic blood pressure and fewer statin users than the placebo arm. On average at each visit, 3 participants in each treatment arm were unable to perform the 6MWT due to contraindications or requiring wheelchair assistance. EMP measurements were incomplete primarily due to insufficient blood collection, the participant refusing to provide blood at the study visit, or poor function of the antibodies for labeling.

\section{Primary Endpoint}

The mean (standard deviation [SD]) percentage of pills taken at the end of the study were 79 (27) and 86 (15) in the fish oil and placebo arms, respectively. The mean percentage change over 6 months in FMD was $-2.6 \%$ (95\% CI -5.6 to 0.3 ) among those randomized to fish oil and $-1.6 \%$ (95\% CI -4.5 to 0.3 ) among those randomized to placebo (Table 2). There was no evidence for a difference in the percentage change in FMD by study arm assessed as the mean difference in maximum post-deflation diameter (-1.1\%; 95\% CI -5.0 to $2.9 ; p=0.59)$ or $55-65$ second deflation diameter (-1.1\%; 95\% CI -3.7 to $1.6 ; p=0.42)$. When we excluded participants using supplemental oxygen, our findings were unchanged (Table S3 in the online supplement).

\section{Secondary Endpoints}

There was no evidence for effect on the secondary measure of systemic endothelial function in RHI (Table 2).

Plasma CD $31^{+}$EMPs increased in the fish oil group by $0.6 \%$ (95\% 0.2 to 1.1$)$ and were unchanged in the placebo group yielding a difference of $0.9 \%$ between the fish oil and placebo groups (95\% CI 0.1 to 1.7 , $p=0.04) . \mathrm{CD} 2 \mathrm{E}^{+}$and $\mathrm{CD} 51^{+}$EMPs also increased with fish oil compared to placebo but these differences included the null value in their 95\% confidence intervals (Table 2).

The SGRQ score decreased by 2.5 (95\% CI -10.0 to 5.0) in the fish oil group and increased by 3.2 (95\% CI -5.5 to 12.0 ) in the placebo group without a significant difference between groups ( $p=0.32$ ) (Table 2). Eight participants in the fish oil arm had a decrease of at least 4 points in the SGRQ score compared to 1 participant in the placebo arm $(p=0.01)$.

The 6MWD did not differ between the fish oil and placebo arms (Table 2). However, improvement in the post-6MWT $\mathrm{SpO}_{2}$ (oxygen saturation) in the fish oil group approached statistical significance (3.9\%, 95\% CI -1.1 to $8.8, p=0.12$ ).

There was no evidence of differences in spirometry or diffusing capacity measures between the fish oil and placebo arms (Table 2). Eighteen (49\%) of the 37 participants who completed the end-of-study questionnaire guessed their treatment assignment incorrectly.

\section{Adverse Events}

None of the participants had an allergic response to fish oil or placebo. During the intervention period, 2 participants had serious adverse events (SAEs). One participant (n-3 PUFA) had a spontaneous pneumothorax that required a hospitalization and was resolved with chest tube placement and pleurodesis and another participant (placebo) died from septic shock secondary to pneumonia. Two participants had SAEs during the post-intervention period: COPD exacerbation ( $n-3$ PUFA) that required a 1-day hospitalization and acute renal insufficiency (n-3 PUFA) secondary to medications 


\section{Figure 1. Flow Chart Based on Consolidated Standards of Reporting Trials}

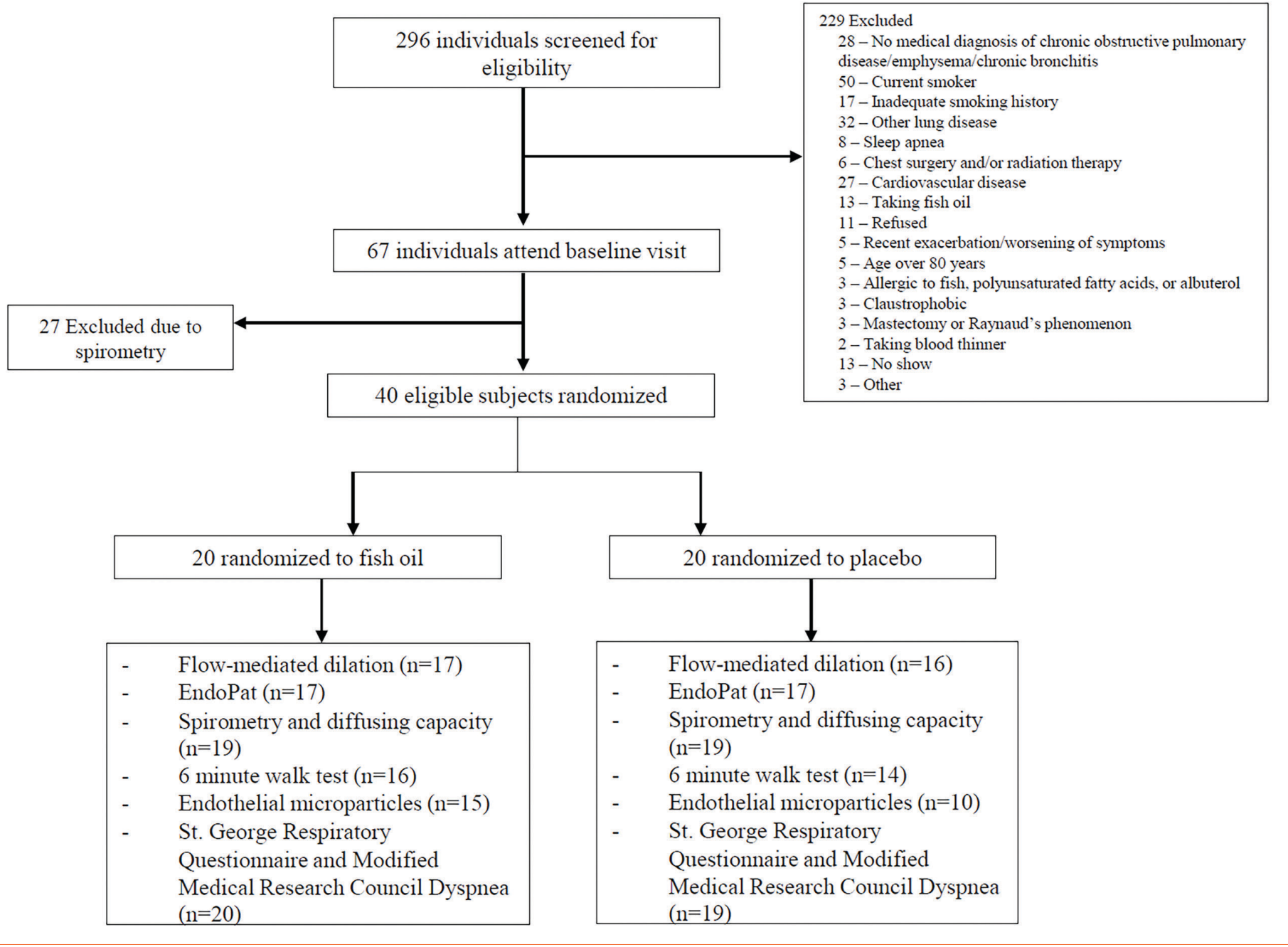

unrelated to the study which resolved without the need for dialysis. The SAEs were determined to be unrelated to the study by the research team and safety monitoring board. Further details regarding these events are in the online supplement (Table S4). There were no significant changes in lipids or alanine aminotransferase levels from baseline to 6 months between the fish oil and placebo groups (Table 3 ).

\section{Discussion}

The n-3 PUFA supplementation did not change systemic endothelial function in stable COPD over 6 months as assessed by FMD in this pilot randomized clinical trial. Among secondary endpoints, plasma CD $31^{+}$EMPs increased and a clinically significant improvement in the SGRQ was more common in the fish oil arm compared to placebo.
Prior studies have shown that n-3 PUFA supplementation improves systemic endothelial function (as measured by FMD) in adults with diabetes, cardiovascular disease, and systemic lupus erythematosus. ${ }^{14,17,24,47}$ Although other studies, including those randomizing patients without these diseases, have been negative. ${ }^{48}$ Such protective effects have been attributed to reducing circulating triglycerides leading to decreased release of plasminogen activator-inhibitor- 1 and increased release of nitric oxide by endothelial cells, ${ }^{49,50}$ which may be relevant to COPD. ${ }^{6}$ Despite these trials and evidence of endothelial dysfunction in COPD, there was no evidence for improvement in endothelial function assessed by FMD, or by EndoPAT, in the current study. Possible reasons for the null findings for FMD in the current study include disease severity, assay sensitivity of the trial, statin use and non- 


\section{Table 1. Baseline Characteristics of Patients}

\begin{tabular}{|c|c|c|c|c|c|}
\hline Characteristic & $\begin{array}{l}\text { Fish Oil } \\
(n=20)\end{array}$ & $\begin{array}{c}\text { Placebo } \\
(n=20)\end{array}$ & Characteristic & $\begin{array}{l}\text { Fish Oil } \\
(n=20)\end{array}$ & $\begin{array}{c}\text { Placebo } \\
(n=20)\end{array}$ \\
\hline Male Sex, No & $10(50)$ & $12(60)$ & \multicolumn{3}{|l|}{ Lipids, mg/dL } \\
\hline Age, years & $67.5(6.5)$ & $66.2(7.5)$ & Total Cholesterol & $187.7(34.4)$ & $190.5(41.9)$ \\
\hline Body Mass Index, $\mathrm{kg} / \mathrm{m}^{2}$ & $27.0(6.4)$ & $30.4(3.6)$ & Triglyercides & $101.8(30.3)$ & $127.8(58.1)$ \\
\hline Cigarette Pack Years & $50.4(29.0)$ & $55.5(34.3)$ & HDL & $63.5(22.2)$ & $54.2(16.3)$ \\
\hline \multicolumn{3}{|l|}{ Race/Ethnicity } & LDL & $103.9(22.8)$ & $110.8(31.2)$ \\
\hline White & $15(75)$ & $16(80)$ & ALT, mg/dL & $19.3(7.2)$ & $23.2(9.9)$ \\
\hline African American & $5(25)$ & $2(10)$ & \multicolumn{3}{|c|}{ Cardiovascular Medication Use } \\
\hline Other & $0(0)$ & $2(10)$ & Statin & $6(30.0)$ & $12(60.0)$ \\
\hline \multicolumn{3}{|l|}{ Education Attainment } & Aspirin & $6(30.0)$ & $8(40.0)$ \\
\hline High school or less & 7 (35) & $7(35)$ & \multirow{3}{*}{$\begin{array}{l}\text { Angiotensin-converting } \\
\text { enzyme inhibitor or } \\
\text { angiotensin II receptor } \\
\text { antagonist }\end{array}$} & \multirow[t]{3}{*}{$6(30.0)$} & \multirow[t]{3}{*}{$5(25.0$} \\
\hline $\begin{array}{l}\text { Some college, associate } \\
\text { degree, or vocational school }\end{array}$ & $4(20)$ & $6(30)$ & & & \\
\hline College degree or more & $9(45)$ & $7(35)$ & & & \\
\hline \multicolumn{3}{|l|}{ COPD Severity $^{a}$} & Calcium channel blocker & $1(5.0)$ & $7(35.0)$ \\
\hline Moderate $\left(50 \%<\mathrm{FEV}_{1}\right.$ & $6(30)$ & $6(30)$ & \multicolumn{3}{|l|}{ COPD Medication Use } \\
\hline$<80 \%$ predicted) & & & \multirow{2}{*}{$\begin{array}{l}\text { Inhaled or systemic } \\
\text { corticosteroids }\end{array}$} & \multirow[t]{2}{*}{$15(75)$} & \multirow[t]{2}{*}{$18(90)$} \\
\hline \multirow{2}{*}{$\begin{array}{l}\text { Severe to very severe } \\
\left(50 \%<\mathrm{FEV}_{1}\right)\end{array}$} & \multirow[t]{2}{*}{$14(70)$} & \multirow[t]{2}{*}{$14(70)$} & & & \\
\hline & & & Short-acting beta2 agonist & $11(55)$ & $10(50)$ \\
\hline Supplemental Oxygen Use & $2(12 \%)$ & $3(19 \%)$ & Long-acting beta 2 agonist & $12(60)$ & $17(85)$ \\
\hline Lung Function & $3(15)$ & $5(25)$ & Short-acting anticholinergic & $3(15)$ & $2(10)$ \\
\hline $\mathrm{FEV}_{1} / \mathrm{FVC}$ & $0.44(0.12)$ & $0.40(0.12)$ & Long-acting anticholinergic & $13(65)$ & $16(80)$ \\
\hline $\mathrm{FEV}_{1}, \%$ predicted & $45.2(13.1)$ & $42.6(16.2)$ & \multicolumn{3}{|l|}{ Flow-mediated Dilation, $\%$} \\
\hline $\mathrm{DLCO}, \mathrm{mL} / \mathrm{min} / \mathrm{mmHg}$ & $12.5(0.1)$ & $14.3(5.4)$ & \multirow{2}{*}{$\begin{array}{l}\text { Maximum post-deflation } \\
\text { diameter }\end{array}$} & \multirow[t]{2}{*}{$6.4(4.7)$} & \multirow[t]{2}{*}{$6.9(5.7)$} \\
\hline $\mathrm{DLCO} / \mathrm{VA}, \mathrm{mL} / \mathrm{min} / \mathrm{mmHg} / \mathrm{L}$ & $3.1(1.0)$ & $2.9(0.8)$ & & & \\
\hline TLC, L & $4.1(1.0)$ & $5.1(1.1)$ & \multirow{2}{*}{$\begin{array}{l}\text { 55-65 second deflation } \\
\text { diameter }\end{array}$} & \multirow[t]{2}{*}{$5.7(4.7)$} & \multirow[t]{2}{*}{$5.5(4.1)$} \\
\hline Emphysema on CT & $13(76 \%)$ & $14(82 \%)$ & & & \\
\hline \multicolumn{3}{|l|}{ Exercise Capacity } & \multicolumn{3}{|c|}{ Endothelial Microparticles, count $/ \mu \mathrm{L}$} \\
\hline \multirow{2}{*}{$\begin{array}{l}\text { 6-minute walk distance, } \\
\text { feet }\end{array}$} & \multirow[t]{2}{*}{$1340(262)$} & \multirow[t]{2}{*}{$1224(290)$} & $\mathrm{CD} 1^{+}$ & \multicolumn{2}{|c|}{1492.4 (900.6) 2453.4 (1651.4) } \\
\hline & & & $\mathrm{CD} 2 \mathrm{E}^{+}$ & $263.7(89.6)$ & $444.0(370.1)$ \\
\hline \multirow{2}{*}{$\begin{array}{l}\text { 6-minute walk test post- } \\
\text { Borg Scale Score }\end{array}$} & $1.9(1.6)$ & $1.7(1.2)$ & $\mathrm{CD}^{2} 1^{+}$ & $1023.7(295.1)$ & $1380.1(629.6)$ \\
\hline & & & SGRQ & $41.1(14.1)$ & $37.0(15.2)$ \\
\hline Systolic Blood Pressure, & $122(16)$ & $133(14)$ & mMRC Dyspnea Scale & $1.55(1.1)$ & $1.45(1.1)$ \\
\hline $\mathrm{mmHg}$ & & & Percentage of Dispensed & $79(27)$ & $86(15)$ \\
\hline Diastolic Blood Pressure, & 74 (11) & $83(7)$ & Pills Taken at End of Study & & \\
\hline
\end{tabular}

$\mathrm{mmHg}$

\begin{tabular}{l|r|r|}
\hline Hypertension & $8(40.0)$ & $10(50.0)$ \\
\hline Diabetes Mellitus, No. (\%) & $2(10.0)$ & $3(15.0)$ \\
\hline
\end{tabular}

${ }^{\mathrm{a}}$ Based on GOLD classification of airflow limitation in COPD

All continuous variables expressed as mean (standard deviation), except endothelial microparticles which are expressed as median (interquartile range)

Categorical variables expressed as number (percentage)

$\mathrm{GOLD}=\mathrm{Global}$ initiative for chronic Obstructive Lung Disease; $\mathrm{COPD}=\mathrm{chronic}$ obstructive lung disease; $\mathrm{FEV} \mathrm{V}_{1}=\mathrm{forced}_{\mathrm{f}} \mathrm{expiratory}$ flow in 1 second; $F V C=$ forced vital capacity; $\mathrm{DLCO}=$ diffusing capacity of the lungs for carbon monoxide; VA=alveolar volume; $\mathrm{TLC}=$ total lung capacity; $\mathrm{CT}=$ computed tomography; HDL=high density lipoprotein; $\mathrm{LDL}=$ low density lipoprotein; $\mathrm{ALT}=\mathrm{alanine}$ aminotransferase; SRGQ=St George's Respiratory Questionnaire; mMRC=modified Medical Research Council 
Table 2. Primary and Secondary Efficacy End Points

\begin{tabular}{|l|l|l|l|l|}
\hline End Point & Fish Oil & Placebo & Difference Between \\
& $(95 \% \mathrm{Cl})$ & $(95 \% \mathrm{Cl})$ & Groups $(95 \% \mathrm{Cl})^{\mathrm{a}}$
\end{tabular}

Primary End Point:

$\mathrm{n}=17$

$\mathrm{n}=16$

Percentage Change in Flow-Mediated Dilation of the Branchial Artery from Baseline to 6 Months

\begin{tabular}{|l|l|l|l|l|}
\hline Maximum post-deflation diameter & $-2.6(-5.6$ to 0.3$)$ & $-1.6(-4.5$ to 1.4$)$ & $-1.1(-5.0$ to 2.9$)$ & 0.59 \\
\hline $55-65$ second deflation diameter & $-1.8(-4.0$ to 0.3$)$ & $-0.8(-2.5$ to 0.9$)$ & $-1.1(-3.7$ to 1.6$)$ & 0.42 \\
\hline
\end{tabular}

Secondary End Points:

Peripheral Arterial Tonometry Change $\mathrm{n}=17$ $\mathrm{n}=17$

from Baseline to 4 Months

\begin{tabular}{|l|r|r|r|r}
\hline Auto RHI & $0.1(-0.2$ to 0.4$)$ & $-0.2(-0.8$ to 0.5$)$ & $0.3(-0.4$ to 1.0$)$ & 0.41 \\
\hline Calculated RHI & $0.01(-0.4$ to 0.4$)$ & $0.2(-0.8$ to 1.2$)$ & $-0.2(-1.2$ to 0.8$)$ & 0.75 \\
\hline Endothelial Microparticles Change from & $\mathrm{n}=15$ & $\mathrm{n}=10$ & & \\
\hline
\end{tabular}

Baseline to 6 Months

log-transformed CD31 $1^{+}, \%$

$0.6(0.2$ to 1.1$)$

$-0.2(-1.1$ to 0.6$)$

$0.9(0.1$ to 1.7$) \quad 0.04$

log-transformed $\mathrm{CD}_{2} \mathrm{E}^{+}, \%$

$0.9(0.6$ to 1.3$) \quad 0.3(-0.5$ to 1.1$)$

log-transformed CD51+, \%

$0.4(0.1$ to 0.7$) \quad 0.01(-0.4$ to 0.5$)$

$0.6(-0.1$ to 1.4$) \quad 0.09$

Symptom, Change Over 6 Months $\mathrm{n}=20$

$\mathrm{n}=19$

modified Medical Research Council

$-0.3(-0.9$ to 0.4$)$

$-0.6(-1.4$ to 0.1$)$

$\begin{array}{ll}0.4(-0.1 \text { to } 0.9) & 0.14\end{array}$

dyspnea scale

SGRQ score

Decrease of 4 or more points in

$-2.5(-10.0$ to 5.0$)$

$8 / 20(40 \%)$

$3.2(-5.5$ to 12.0$)$

$1 / 19(5 \%)$

$0.4(-0.6$ to 1.3$) \quad 0.42$

SGRQ, change at 6 months

$\begin{aligned} & \text { 6-Minute Walk Distance, Change Over } \\ & 6 \text { Months }\end{aligned}$
n=16

6MWD, feet

6MWT post-Borg scale score

-26.9 (-130.9 to 77.1$) 65.2(-161.4$ to 291.7$)-90.2(-299.4$ to 119.1$) \quad 0.39$

$\mathrm{SpO}_{2}$ resting, \%

$0.4(-1.1$ to 1.9$) \quad-0.4(-2.2$ to 1.4$)$

$0.2(-1.3$ to 1.8$) \quad-0.1(-2.9$ to 2.6$)$

\begin{tabular}{ll}
$0.8(-1.4$ to 3.0$)$ & 0.46 \\
\hline
\end{tabular}

$\mathrm{SpO}_{2}$ post-6MWT, \%

$2.0(-1.01$ to 4.9$)$

$-1.6(-5.7$ to 2.4$)$

$0.4(-2.6$ to 3.4$) \quad 0.80$

Pulmonary Function, Change Over

6 Months

Change in $\mathrm{FEV}_{1}$

Percent predicted $\mathrm{FEV}_{1}, \%$

$\mathrm{FEV}_{1}, \mathrm{~L}$

$\mathrm{n}=19$

$\mathrm{n}=19$

$3.9(-1.1$ to 8.8$)$

0.12

Change in FVC

FVC, L

Change in DLCO

DLCO, $\mathrm{mL} / \mathrm{min} / \mathrm{mmHg}$

DLCO/VA ratio, $\mathrm{mL} / \mathrm{min} / \mathrm{mmHg}$

Change in $\mathrm{FEV}_{1} / \mathrm{FVC}$

$\mathrm{FEV}_{1} / \mathrm{FVC}$

$-0.7(-3.9$ to 2.5$)$

-2.9 (-6.3 to 0.4$)$

$0.8(-4.8$ to 6.4$) \quad 0.78$

\begin{tabular}{lll|l|l|}
$-0.02(-0.1$ to 0.1$)$ & $-0.09(-0.2$ to 0.004$)$ & $0.02(-0.14$ to 0.18$)$ & 0.81
\end{tabular}

Difference between groups=(fish oil arm-placebo)

$\mathrm{RHI}=$ reactive hyperemia index; SGRQ=St George's respiratory questionnaire; $6 \mathrm{MWD}=6$-minute walk distance; $6 \mathrm{MWT}=6$-minute

walk test; $\mathrm{SpO}_{2}=$ oxygen saturation; $\mathrm{FEV}_{1}=$ forced expiratory flow in one second; $\mathrm{FVC}=$ forced vital capacity; $\mathrm{DLCO}=$ diffusing

capacity of the lungs for carbon monoxide; $\mathrm{VA}=$ alveolar volume

adherence. A high percentage of study participants

had severe COPD in whom FMD may be more a

to therapy. Endothelial dysfunction in COPD extends

function of hypoxemia and, therefore, less amenable

to mild $\mathrm{COPD},{ }^{9}$ a group that may be more amenable

to effects of n-3 PUFAs. Prior studies that showed 


\section{Table 3. Safety Measures by Treatment Assignment}

\begin{tabular}{l|r|r|r|r}
$\begin{array}{l}\text { Safety Measures } \\
\text { Lipids }\end{array}$ & $\begin{array}{c}\text { Mean Change }(95 \% \mathrm{Cl}) \\
\text { Fish Oil }\end{array}$ & $\begin{array}{c}\text { Mean Change } \\
\text { (95\% Cl) Placebo }\end{array}$ & $\begin{array}{c}\text { Difference Between } \\
\text { Groups (95\% Cl) }\end{array}$ & $p$-value \\
\hline Total cholesterol, $\mathrm{mg} / \mathrm{dL}$ & $-3.4(-20.8$ to 14.1$)$ & $-18.5(-36.0$ to -1.0$)$ & $15.9(-8.6$ to 40.4$)$ & 0.20 \\
\hline Triglyceride, $\mathrm{mg} / \mathrm{dL}$ & $-5.3(-29.7$ to 19.1$)$ & $-19.4(-44.7$ to 6.0$)$ & $14.0(-21.7$ to 49.8$)$ & 0.44 \\
\hline High-density lipoprotein, $\mathrm{mg} / \mathrm{dL}$ & $-0.2(-10.2$ to 9.8$)$ & $-1.3(-8.2$ to 5.5$)$ & $1.2(-10.5$ to 13.0$)$ & 0.84 \\
\hline Low-density lipoprotein, $\mathrm{mg} / \mathrm{dL}$ & $-0.9(-14.7$ to 12.9$)$ & $-12.8(-28.3$ to 2.7$)$ & $11.6(-8.2$ to 31.3$)$ & 0.25 \\
\hline Alanine aminotransferase $\mathrm{mg} / \mathrm{dL}$ & $5.3(1.1$ to 9.4$)$ & $-3.8(-9.5$ to 1.8$)$ & $6.0(-1.7$ to 13.8$)$ & 0.13 \\
\hline
\end{tabular}

${ }^{\mathrm{a} D i f f e r e n c e ~ b e t w e e n ~ g r o u p s=(f i s h ~ o i l ~ a r m-p l a c e b o) ~}$

marked increases in FMD with n-3 PUFAs had larger sample sizes $(n>60)$ compared to this study of 40 participants. ${ }^{4,48}$ Although there was no suggestion of benefit for FMD, the n-3 PUFA composition varied compared to prior studies, which had higher doses of $\mathrm{DHA},{ }^{47,51}$ and bronchodilators might have interfered with measurements. Statins have a large effect on FMD and were used more commonly in the placebo than intervention group, which might have biased our study to the null. ${ }^{52}$ Non-adherence to treatment is another consideration as the triglycerides levels in the fish oil group did not significantly decrease. Protocol compliance, although high overall, was lower in the fish oil arm compared to placebo arm, which may have biased results toward the null. We did not measure DHA and EPA levels in the participants' blood to confirm treatment adherence or dosage effect.

Nonetheless, we observed a change in plasma CD $31^{+}$EMPs in the fish oil group, which suggests an effect, albeit in the opposite direction of that hypothesized and observed in a recent small trial of adults at risk for cardiovascular disease. ${ }^{53} \mathrm{CD} 31^{+}$ EMPs are vesicles shed from endothelial plasma membranes upon perturbation, and $C D 31^{+}$EMPs are markers of endothelial cell apoptosis. ${ }^{32} \mathrm{CD} 31^{+}$EMPs are elevated in smokers and adults with COPD and are associated with greater disease severity, emphysema, and exacerbations in cross-sectional studies. ${ }^{11,54}$ This finding suggests that $n-3$ PUFAs have a biological effect on the endothelium in COPD, although whether it may deleterious or beneficial is unclear. Pre-clinical studies have shown DHA may induce cellular apoptosis via phosphorylation of p53 and induction of caspase 3 activation, including vascular smooth and human endothelial cells. ${ }^{55,56} \mathrm{DHA}$ was a large component of the $\mathrm{n}-3$ supplementation we used which may have contributed to our EMP findings in the opposite hypothesized direction. We exercise caution in over-interpretation of this finding as this was a secondary endpoint and we did not statistically correct for multiple secondary outcomes.

More participants in the fish oil group than the placebo group reported improvement in their SGRQ. This may be a false positive or might suggest that n-3 PUFAs might have some benefit in COPD by other mechanisms. Arachidonic acid (AA, 20:4, $\mathrm{n}-6)$, an omega-6 fatty acid, is highly prevalent in inflammatory cell membranes and is a precursor to eicosanoids that are key inflammatory mediators. ${ }^{57}$ Decreased production of these eicosanoids (prostaglandin E2 and 4 series-leukotrienes) following intake of DHA and EPA has been described in humans. ${ }^{58,59}$ Reduced bronchial inflammation and AA-derived eicosanoid secretion by leukocytes following omega-3 supplementation has been observed in sensitized allergic asthmatics. ${ }^{60} \mathrm{DHA}$ and EPA are agonists of peroxisome proliferatoractivated receptor gamma (PPAR-gamma), which is a nuclear hormone receptor that is expressed in the airway epithelium. ${ }^{61} \mathrm{DHA}$ and EPA are precursors to specialized pro-resolving lipid mediators (SPMs) that are critical in the resolution of inflammation. ${ }^{62}$ Treatment of human macrophages with $n-3$ derived SPMs attenuates cigarette smoke-induced inflammation as serum and bronchoalveolar lavage fluid SPM levels are reduced in patients with COPD. ${ }^{63}$

Our study has several limitations. Despite randomization and achieving our enrollment goal and blinding, there was still an imbalance of characteristics between the fish oil and placebo arms. We cannot completely rule out that vitamin $\mathrm{E}$, a component of our fish oil treatment that has antioxidant properties, may have contributed to our positive findings (ex. change in SGRQ). However, the dose of vitamin E in our study was much lower than doses used in prior 
clinical trials. ${ }^{64}$ There were more calcium channel blocker (CCB) users in the placebo arm than fish oil arm. CCBs have been shown to increase FMD, and, therefore, may have biased our results to the null. ${ }^{65}$ We did not have complete primary and secondary endpoint measurements in all of our participants, which reduced the power for some endpoints. A notable number of participants did not complete testing for some of our secondary outcomes. This was due to the participant's inability to perform the testing (ex. 6MWT) or poor blood sample collection due to difficulty drawing blood or the participant refusing. We did not a priori adjust for multiple secondary outcome measurements and, therefore, interpretation of secondary endpoints should be taken with caution. Finally, we did not measure blood levels of DHA and EPA to assess adherence to treatment.

\section{Conclusion}

In conclusion, n-3 PUFA supplementation with fish oil did not change systemic endothelial function assessed by FMD in COPD. CD $31^{+}$EMPs increased, suggesting an effect on the endothelium, and one measure of overall health status improved, which might warrant examination in larger studies.

\section{Acknowledgements}

Author's Contributions: RGB was responsible for conception and design of the study. MAT, NHY, $\mathrm{KMB}, \mathrm{CMLC}, \mathrm{DS}$, and RGB were responsible for data acquisition. JSK, MAT, RGB provided analysis of the data. JSK and MAT drafted the initial manuscript. All authors contributed to the data interpretation and edited the manuscript for important scientific content. All of the authors agree to be accountable for all aspects of the work in regard to accuracy and integrity.

\section{Declaration of Interest}

Omax-3 and placebo were provided by an in-kind donation from Cenestra Health. RGB reports grant funding unrelated to the project from the COPD and Alpha-1 Foundations. No other authors have relevant interests to declare. 


\section{References}

1. Lozano R, Naghavi M, Foreman K, et al. Global and regional mortality from 235 causes of death for 20 age groups in 1990 and 2010: a systematic analysis for the Global Burden of Disease Study 2010. Lancet. 2012;380(9859):2095-2128.

doi: https://doi.org/10.1016/S0140-6736(12)61728-0

2. Ni H, Xu J. COPD-related mortality by sex and race among adults aged 25 and over: United States, 2000-2014. NCHS Data Brief. 2016(256):1-8.

3. Vogelmeier CF, Criner GJ, Martinez FJ, et al. Global strategy for the diagnosis, management, and prevention of chronic obstructive lung disease 2017 Report. GOLD Executive Summary. Am J Respir Crit Care Med. 2017;195(5):557-582.

doi: https://doi.org/10.1164/rccm.201701-0218PP

4. McDonough JE, Yuan R, Suzuki M, et al. Small-airway obstruction and emphysema in chronic obstructive pulmonary disease. $N$ Engl $J$ Med. 2011;365(17):1567-1575.

doi: https://doi.org/10.1056/NEJMoa1106955

5. Kesimer M, Ford AA, Ceppe A, et al. Airway mucin concentration as a marker of chronic bronchitis. N Engl J Med. 2017;377(10):911-922. doi: https://doi.org/10.1056/NEJMoa1701632

6. Polverino F, Celli BR, Owen CA. COPD as an endothelial disorder: endothelial injury linking lesions in the lungs and other organs? (2017 Grover Conference Series). Pulm Circ. 2018;8(1):2045894018758528. doi: https://doi.org/10.1177/2045894018758528

7. Kasahara Y, Tuder RM, Cool CD, Lynch DA, Flores SC, Voelkel NF. Endothelial cell death and decreased expression of vascular endothelial growth factor and vascular endothelial growth factor receptor 2 in emphysema. Am J Respir Crit Care Med. 2001;163(3 Pt 1):737-744. doi: https://doi.org/10.1164/ajrccm.163.3.2002117

8. Santos S, Peinado VI, Ramirez J, et al. Enhanced expression of vascular endothelial growth factor in pulmonary arteries of smokers and patients with moderate chronic obstructive pulmonary disease. Am J Respir Crit Care Med. 2003;167(9):1250-1256.

doi: https://doi.org/10.1164/rccm.200210-12330C

9. Peinado VI, Barbera JA, Ramirez J, et al. Endothelial dysfunction in pulmonary arteries of patients with mild COPD. Am J Physiol. 1998;274(6 Pt 1):L908-913.

doi: https://doi.org/10.1152/ajplung.1998.274.6.L908

10. Barr RG, Mesia-Vela S, Austin JH, et al. Impaired flow-mediated dilation is associated with low pulmonary function and emphysema in ex-smokers: the Emphysema and Cancer Action Project (EMCAP) Study. Am J Respir Crit Care Med. 2007;176(12):1200-1207. doi: https://doi.org/10.1164/rccm.200707-9800C

11. Thomashow MA, Shimbo D, Parikh MA, et al. Endothelial microparticles in mild chronic obstructive pulmonary disease and emphysema. The Multi-Ethnic Study of Atherosclerosis Chronic Obstructive Pulmonary Disease study. Am J Respir Crit Care Med. 2013;188(1):60-68. doi: https://doi.org/10.1164/rccm.201209-1697OC
12. Clarenbach CF, Senn O, Sievi NA, et al. Determinants of endothelial function in patients with COPD. Eur Respir J. 2013;42(5):1194-1204. doi: https://doi.org/10.1183/09031936.00144612

13. Blum A, Simsolo C, Sirchan R. Vascular responsiveness in patients with chronic obstructive pulmonary disease (COPD). Eur J Intern Med. 2014;25(4):370-373.

doi: https://doi.org/10.1016/j.ejim.2013.03.017

14. Wang Q, Liang X, Wang L, et al. Effect of omega-3 fatty acids supplementation on endothelial function: a meta-analysis of randomized controlled trials. Atherosclerosis. 2012;221(2):536-543. doi: https://doi.org/10.1016/j.atherosclerosis.2012.01.006

15. Abeywardena MY, Head RJ. Longchain n-3 polyunsaturated fatty acids and blood vessel function. Cardiovasc Res. 2001;52(3):361-371. doi: https://doi.org/10.1016/S0008-6363(01)00406-0

16. He K, Liu K, Daviglus ML, et al. Associations of dietary long-chain n-3 polyunsaturated fatty acids and fish with biomarkers of inflammation and endothelial activation (from the Multi-Ethnic Study of Atherosclerosis [MESA]). Am J Cardiol. 2009;103(9):1238-1243. doi: https://doi.org/10.1016/j.amjcard.2009.01.016

17. Johansen O, Seljeflot I, Hostmark AT, Arnesen H. The effect of supplementation with omega-3 fatty acids on soluble markers of endothelial function in patients with coronary heart disease. Arterioscler Thromb Vasc Biol. 1999;19(7):1681-1686. doi: https://doi.org/10.1161/01.ATV.19.7.1681

18. Haberka M, Mizia-Stec K, Mizia M, et al. N-3 polyunsaturated fatty acids early supplementation improves ultrasound indices of endothelial function, but not through NO inhibitors in patients with acute myocardial infarction: N-3 PUFA supplementation in acute myocardial infarction. Clin Nutr. 2011;30(1):79-85. doi: https://doi.org/10.1016/j.clnu.2010.07.011

19. Kromhout D, Giltay EJ, Geleijnse JM, Alpha Omega Trial Group. n-3 fatty acids and cardiovascular events after myocardial infarction. $N$ Engl J Med. 2010;363(21):2015-2026.

doi: https://doi.org/10.1056/NEJMoa1003603

20. Rauch B, Schiele R, Schneider S, et al. OMEGA, a randomized, placebo-controlled trial to test the effect of highly purified omega-3 fatty acids on top of modern guideline-adjusted therapy after myocardial infarction. Circulation. 2010;122(21):2152-2159. doi: https://doi.org/10.1161/CIRCULATIONAHA.110.948562

21. Aung T, Halsey J, Kromhout D, et al. Associations of omega-3 fatty acid supplement use with cardiovascular disease risks: meta-analysis of 10 trials involving 77917 individuals. JAMA Cardiol. 2018;3(3):225234. doi: https://doi.org/10.1001/jamacardio.2017.5205

22. Shahar E, Folsom AR, Melnick SL, et al. Dietary n-3 polyunsaturated fatty acids and smoking-related chronic obstructive pulmonary disease. Atherosclerosis Risk in Communities Study Investigators. $N$ Engl J Med. 1994;331(4):228-233.

doi: https://doi.org/ 10.1056/NEJM199407283310403 
23. Varraso R, Barr RG, Willett WC, Speizer FE, Camargo CA, Jr. Fish intake and risk of chronic obstructive pulmonary disease in 2 large US cohorts. Am J Clin Nutr. 2015;101(2):354-361.

doi: https://doi.org/10.3945/ajcn.114.094516

24. Goodfellow J, Bellamy MF, Ramsey MW, Jones CJ, Lewis MJ. Dietary supplementation with marine omega-3 fatty acids improve systemic large artery endothelial function in subjects with hypercholesterolemia. J Am Coll Cardiol. 2000;35(2):265-270. doi: https://doi.org/10.1016/S0735-1097(99)00548-3

25. Rizza S, Tesauro M, Cardillo C, et al. Fish oil supplementation improves endothelial function in normoglycemic offspring of patients with type 2 diabetes. Atherosclerosis. 2009;206(2):569-574. doi: https://doi.org/10.1016/j.atherosclerosis.2009.03.006

26. Corretti MC, Anderson TJ, Benjamin EJ, et al. Guidelines for the ultrasound assessment of endothelial-dependent flow-mediated vasodilation of the brachial artery: a report of the International Brachial Artery Reactivity Task Force. J Am Coll Cardiol. 2002;39(2):257-265. doi: https://doi.org/10.1016/S0735-1097(01)01746-6

27. Neunteufl T, Heher S, Katzenschlager R, et al. Late prognostic value of flow-mediated dilation in the brachial artery of patients with chest pain. Am J Cardiol. 2000;86(2):207-210.

doi: https://doi.org/10.1016/S0002-9149(00)00857-2

28. Gokce N, Keaney JF, Jr., Hunter LM, et al. Predictive value of noninvasively determined endothelial dysfunction for long-term cardiovascular events in patients with peripheral vascular disease. $J$ Am Coll Cardiol. 2003;41(10):1769-1775.

doi: https://doi.org/10.1016/S0735-1097(03)00333-4

29. Hamburg NM, Keyes MJ, Larson MG, et al. Cross-sectional relations of digital vascular function to cardiovascular risk factors in the Framingham Heart Study. Circulation. 2008;117(19):2467-2474. doi: https://doi.org/ 10.1161/CIRCULATIONAHA.107.748574

30. Rubinshtein R, Kuvin JT, Soffler M, et al. Assessment of endothelial function by non-invasive peripheral arterial tonometry predicts late cardiovascular adverse events. Eur Heart J. 2010;31(9):1142-1148. doi: https://doi.org/10.1093/eurheartj/ehq010

31. Bernal-Mizrachi L, Jy W, Jimenez JJ, et al. High levels of circulating endothelial microparticles in patients with acute coronary syndromes. Am Heart J. 2003;145(6):962-970.

doi: https://doi.org/10.1016/S0002-8703(03)00103-0

32. Jimenez JJ, Jy W, Mauro LM, Soderland C, Horstman LL, Ahn YS. Endothelial cells release phenotypically and quantitatively distinct microparticles in activation and apoptosis. Thromb Res. 2003;109(4):175-180.

doi: https://doi.org/10.1016/S0049-3848(03)00064-1

33. Miller MR, Hankinson J, Brusasco V, et al. Standardisation of spirometry. Eur Respir J. 2005;26(2):319-338.

doi: https://doi.org/10.1183/09031936.05.00034805
34. Hankinson JL, Kawut SM, Shahar E, Smith LJ, Stukovsky KH, Barr RG. Performance of American Thoracic Society-recommended spirometry reference values in a multiethnic sample of adults: the multi-ethnic study of atherosclerosis (MESA) lung study. Chest. 2010;137(1):138-145. doi: https://doi.org/10.1378/chest.09-0919

35. Celli BR, MacNee W. Standards for the diagnosis and treatment of patients with COPD: a summary of the ATS/ERS position paper. Eur Respir J. 2004;23(6):932-946.

doi: https://doi.org/10.1183/09031936.04.00014304

36. Global Initiative for Chronic Obstructive Lung Disease (GOLD). Global strategy for the diagnosis, management, and prevention of COPD. GOLD website. Published 2011. Updated December 2011. Accessed April 2020. http:/ /www.goldcopd.org

37. Bhatt SP, Balte PP, Schwartz JE, et al. Discriminative accuracy of $\mathrm{FEV}_{1}$ :FVC thresholds for COPD-related hospitalization and mortality. JAMA. 2019;321(24):2438-2447.

doi: https://doi.org/10.1001/jama.2019.7233

38. Hankinson J, Odencrantz J, Fedan K. Spirometric reference values from a sample of the general US population. Am J Respir Crit Care Med. 1999;159(1):179-187.

doi: https://doi.org/10.1164/ajrccm.159.1.9712108

39. Macintyre N, Crapo RO, Viegi G, et al. Standardisation of the singlebreath determination of carbon monoxide uptake in the lung. Eur Respir J. 2005;26(4):720-735.

doi: https://doi.org/10.1183/09031936.05.00034905

40. Jones RS, Meade F. A theoretical and experimental analysis of anomalies in the estimation of pulmonary diffusing capacity by the single breath method. Q J Exp Physiol Cogn Med Sci. 1961;46(2):131143. doi: https://doi.org/10.1113/expphysiol.1961.sp001525

41. ATS Committee on Proficiency Standards for Clinical Pulmonary Function Laboratories. ATS statement: guidelines for the six-minute walk test. Am J Respir Crit Care Med. 2002;166(1):111-117. doi: https://doi.org/10.1164/ajrccm.166.1.at1102

42. Mahler DA, Wells CK. Evaluation of clinical methods for rating dyspnea. Chest. 1988;93(3):580-586.

doi: https://doi.org/10.1378/chest.93.3.580

43. Jones PW, Quirk FH, Baveystock CM. The St George's Respiratory Questionnaire. Respir Med. 1991;85 (Suppl B):25-31. doi: https://doi.org/10.1016/S0954-6111(06)80166-6

44. Jones PW, Quirk FH, Baveystock CM, Littlejohns P. A self-complete measure of health status for chronic airflow limitation. The St George's Respiratory Questionnaire. Am Rev Respir Dis. 1992;145(6):13211327. doi: https://doi.org/10.1164/ajrccm/145.6.1321

45. Cooke F, Bullen C, Whittaker R, McRobbie H, Chen MH, Walker N. Diagnostic accuracy of NicAlert cotinine test strips in saliva for verifying smoking status. Nicotine Tob Res. 2008;10(4):607-612. doi: https://doi.org/10.1080/14622200801978680 
46. Jones PW. St George's Respiratory Questionnaire: MCID. COPD. 2005;2(1):75-79. doi: https://doi.org/10.1081/COPD-200050513

47. Wright SA, O’Prey FM, McHenry MT, et al. A randomised interventional trial of omega-3-polyunsaturated fatty acids on endothelial function and disease activity in systemic lupus erythematosus. Ann Rheum Dis. 2008;67(6):841-848. doi: https://doi.org/10.1136/ard.2007.077156

48. Oh PC, Koh KK, Sakuma I, et al. Omega-3 fatty acid therapy dosedependently and significantly decreased triglycerides and improved flow-mediated dilation, however, did not significantly improve insulin sensitivity in patients with hypertriglyceridemia. Int $J$ Cardiol. 2014;176(3):696-702.

doi: https://doi.org/10.1016/j.ijcard.2014.07.075

49. Stiko-Rahm A, Wiman B, Hamsten A, Nilsson J. Secretion of plasminogen activator inhibitor-1 from cultured human umbilical vein endothelial cells is induced by very low-density lipoprotein. Arteriosclerosis. 1990;10(6):1067-1073. doi: https://doi.org/10.1161/01.ATV.10.6.1067

50. Okuda Y, Kawashima K, Sawada T, et al. Eicosapentaenoic acid enhances nitric oxide production by cultured human endothelial cells. Biochem Biophys Res Commun. 1997;232(2):487-491. doi: https://doi.org/10.1006/bbrc.1997.6328

51. Mindrescu C, Gupta RP, Hermance EV, et al. Omega-3 fatty acids plus rosuvastatin improves endothelial function in South Asians with dyslipidemia. Vasc Health Risk Manag. 2008;4(6):1439-1447. doi: https://doi.org/10.2147/VHRM.S4001

52. Strey CH, Young JM, Lainchbury JH, et al. Short-term statin treatment improves endothelial function and neurohormonal imbalance in normocholesterolaemic patients with non-ischaemic heart failure. Heart. 2006;92(11):1603-1609.

doi: https://doi.org/10.1136/hrt.2005.082560

53. Wu SY, Mayneris-Perxachs J, Lovegrove JA, Todd S, Yaqoob P. Fish-oil supplementation alters numbers of circulating endothelial progenitor cells and microparticles independently of eNOS genotype. Am J Clin Nutr. 2014;100(5):1232-1243.

doi: https://doi.org/10.3945/ajcn.114.088880

54. Takahashi T, Kobayashi S, Fujino N, et al. Increased circulating endothelial microparticles in COPD patients: a potential biomarker for COPD exacerbation susceptibility. Thorax. 2012;67(12):1067-1074. doi: https://doi.org/10.1136/thoraxjn1-2011-201395

55. Diep QN, Intengan HD, Schiffrin EL. Endothelin-1 attenuates omega3 fatty acid-induced apoptosis by inhibition of caspase 3. Hypertension. 2000;35(1 Pt 2):287-291.

doi: https://doi.org/10.1161/01.HYP.35.1.287

56. Kim HJ, Vosseler CA, Weber PC, Erl W. Docosahexaenoic acid induces apoptosis in proliferating human endothelial cells. J Cell Physiol. 2005;204(3):881-888.

doi: https://doi.org/10.1002/jcp.20351
57. Calder PC. Omega-3 polyunsaturated fatty acids and inflammatory processes: nutrition or pharmacology? $\mathrm{Br} J$ Clin Pharmacol. 2013;75(3):645-662.

doi: https://doi.org/10.1111/j.1365-2125.2012.04374.x

58. von Schacky C, Kiefl R, Jendraschak E, Kaminski WE. n-3 fatty acids and cysteinyl-leukotriene formation in humans in vitro, ex vivo, and in vivo. J Lab Clin Med. 1993;121(2):302-309.

59. Trebble TM, Wootton SA, Miles EA, et al. Prostaglandin E2 production and $\mathrm{T}$ cell function after fish-oil supplementation: response to antioxidant cosupplementation. Am J Clin Nutr. 2003;78(3):376-382. doi: https://doi.org/10.1093/ajcn/78.3.376

60. Schubert R, Kitz R, Beermann C, et al. Effect of n-3 polyunsaturated fatty acids in asthma after low-dose allergen challenge. Int Arch Allergy Immunol. 2009;148(4):321-329. doi: https://doi.org/10.1159/000170386

61. Honda K, Marquillies P, Capron M, Dombrowicz D. Peroxisome proliferator-activated receptor gamma is expressed in airways and inhibits features of airway remodeling in a mouse asthma model. $J$ Allergy Clin Immunol. 2004;113(5):882-888.

doi: https://doi.org/10.1016/j.jaci.2004.02.036

62. Serhan CN, Chiang N, Van Dyke TE. Resolving inflammation: dual anti-inflammatory and pro-resolution lipid mediators. Nat Rev Immunol. 2008;8(5):349-361. doi: https://doi.org/10.1038/nri2294

63. Croasdell A, Thatcher TH, Kottmann RM, et al. Resolvins attenuate inflammation and promote resolution in cigarette smoke-exposed human macrophages. Am J Physiol Lung Cell Mol Physiol. 2015;309(8):L888-901.

doi: https://doi.org/10.1152/ajplung.00125.2015

64. Agler AH, Kurth T, Gaziano JM, Buring JE, Cassano PA. Randomised vitamin $\mathrm{E}$ supplementation and risk of chronic lung disease in the Women's Health Study. Thorax. 2011;66(4):320-325. doi: https://doi.org/10.1136/thx.2010.155028

65. Oshima T, Ozono R, Yano Y, et al. Beneficial effect of T-type calcium channel blockers on endothelial function in patients with essential hypertension. Hypertens Res. 2005;28(11):889-894. doi: https://doi.org/10.1291/hypres.28.889 